Marmara Üniversitesi Siyasal Bilimler Dergisi • Marmara University Journal of Political Science • Cilt 5, Özel Sayı, Nisan 20I7, ISSN 2I47-6934, ss. 3I-49 • DOI: xxxx

\title{
Karadeniz Ekonomik İşbirliği Örgütü (KEİ) Üyesi Ülkelerin Küresel Pazarlardaki Karşılaştırmalı Üstünlükleri
}

\author{
Birol ERKAN* \\ Şule BATBAYLI ${ }^{\star *}$
}

Öz

Karadeniz Ekonomik İşbirliği Örgütü (KEİ), Karadeniz havzasının gerek siyasi gerekse ekonomik açıdan istikrarlı ve söz sahibi olmasını amaçlamaktadır. Bununla birlikte, 12 üye ülkeden oluşan Örgüt, kuruluşundan bu yana küresel anlamda potansiyelini tam olarak sergileyememiştir.

$\mathrm{Bu}$ çalışmanın amacı, Karadeniz Ekonomik İşbirliği Örgütü üyesi ülkelerin küresel pazarlardaki karşılaştırmalı üstünlüklerini ve rekabet gücünü ortaya koymaktır. Çalışmada elde edilen sonuçlar, KEİ ülkelerinin uluslararası pazarlarda genellikle hammadde ve emek yoğun ürünlerin ihracatında karşılaştırmalı üstünlüklere sahip olduğunu göstermektedir. Bununla birlikte, sözü edilen ülkelerin, ar-ge ve teknoloji yoğun ürünlerin ihracatında küresel pazarlarda rekabet dezavantajı bulunmaktadır.

Anahtar kelimeler: KEİ, Açıklanmış Karşılaştırmalı Üstünlükler, Balassa İndeksi, Vollrath İndeksi.

\section{Comparative Advantages in The Global Markets of The Countries of The Organization of The Black Sea Economic Cooperation (BSEC)}

\begin{abstract}
The Black Sea Economic Cooperation (BSEC) aims to ensure that the Black Sea basin is stable and committed both politically and economically. Nevertheless, the Organization which is composed of 12 member countries has been fully displaying its global potential since its inception.

The aim of this study is to demonstrate the comparative advantages and competitiveness of the countries of the Black Sea Economic Cooperation Organization in the global markets. The results of the study show that BSEC countries generally have comparative advantages in the export of raw materials and labor intensive products in international markets. At the same time, The mentioned countries have a competitive disadvantage in the global markets in the export of R\&D and technology intensive products.
\end{abstract}

Keywords: BSEC, Revealed Comparative Advantages, Balassa Index, Vollrath Index.

* Doç. Dr., Uşak Üniversitesi, İİBF, İktisat Bölümü, birol.erkan@usak.edu.tr

* Yüksek Lisans Öğrencisi, Uşak Üniversitesi, İİBF, İktisat Bölümü, batbaylisule45@gmail.com 


\section{Giriş}

Günümüzde, ülkelerin (toplulukların) ihracatlarının artmasıyla birlikte, hangi sektörlerdeki ve ürün gruplarındaki ihracatlarının ve dış ticaret sonucunda elde edilen katma değerlerin artmış olduğu da önemli bir gelişmişlik göstergesi olarak karşımıza çıkmaktadır. Bu bağlamda küresel rekabette kazançlı çıkan ülkeler, dış ticaret sonucu daha fazla katma değer sağlayanlar olarak karşımıza çıkmaktadır. Bu bağlamda, uluslararası piyasalarda ortaya çıkacak katma değerden en büyük payı alma çabası, ülkeler ve ülke grupları (bölgesel birlikler, örgütler) arasındaki ihracat rekabet artışını da beraberinde getirmektedir.

$\mathrm{Bu}$ çalı̧̧mada, Karadeniz Ekonomik İşbirliği Örgütü (KEİ) üyesi ülkelerin ihracat performanslarının ve rekabet profilinin ürün grubu bazında ortaya koyulması ve Örgütün küresel rekabet edebilirliğinin saptanması amaçlanmıştır. Bu perspektifte, ülkelerin ihracatındaki karşılaştırmalı üstünlüklerin ve küresel rekabet güçlerinin ölçülebilmesi bağlamında "Açıklanmış Karşılaştırmalı Üstünlük Katsayıları" kullanılmıştır.

Çalışmanın birinci bölümünde KEİ’nin kuruluşuna ve makro-ekonomik görünümüne ilişkin temel tanıtıcı bilgiler verilmiştir. İkinci bölümde, dış ticaretin temel belirleyicisi olarak karşılaştırmalı üstünlük kavramına teorik açıdan değinilmiştir. Bu bağlamda, karşılaştırmalı üstünlüklerin ölçümünde kullanılan Balassa İndeksi, Vollrath İndeksi ve İhracat Benzerlik İndeksi teorik bazda tanıtılmaya çalışılmıştır. Üçüncü bölümde ise KEİ ekonomilerinin ihracat karşılaştırmalı üstünlük ve dezavantaj durumunun ortaya koyulabilmesi maksadıyla ürün grubu bazında açıklanmış karşılaştırmalı üstünlük indeksleri hesaplanmıştır.

\section{Karadeniz Ekonomik İşbirliği Örgütü (KEi)}

Karadeniz Ekonomik İşbirliği Örgütü (KEİ), 1992 yllında İstanbul'da imzalanan bir anlaşmayla kurulmuştur. Anlaşmayı imzalayan ülkeler, Karadenize sahili olan Türkiye, Rusya, Ukrayna, Moldova, Gürcistan, Romanya ve Bulgaristan ile Karadenize kıyısı bulunmayan Arnavutluk, Yunanistan, Ermenistan ve Azerbaycan'dır. Anlaşmayı imzalayan ülkeler, Türkiye ve Yunanistan hariç tutulursa, SSCB'nin ve COMECON'un dağılmasıyla ortaya çıkmış ülkelerdir (Ertürk, 2002). 1980'li yılların sonunda, Doğu Avrupa’da, ekonomik boyutta serbest piyasa ekonomisine ve Siyasal boyutta çoğulcu demokrasiye geçiş sürecinin oluşturduğu ortamda, konumunu ve zamanlamasını bulan KEİ fikri, öncülüğünü Türkiye’nin yaptığı bir bölgesel ekonomik işbirliği girişimidir (Güran ve Aktürk, 1995).

KEİ’nin günümüzde 12 üye ülkesi bulunmakta olup, bu ülkeler; Arnavutluk, Azerbaycan, Bulgaristan, Ermenistan, Gürcistan, Moldova, Romanya, Rusya Federasyonu, Ukrayna, Yunanistan, Sırbistan ve Türkiyedir. Ayrıca; ABD, AB Komisyonu, Almanya, Avusturya, Beyaz Rusya, Çek Cumhuriyeti, Hırvatistan, İsrail, İtalya, Mısır, Polonya, Slovak Cumhuriyeti, Tunus ise örgüt bünyesinde gözlemci statüsünde yer almaktadır. ${ }^{1}$

$\overline{1}$ Üye ülkelerle ilgili bilgi için bkz http://ab.gtb.gov.tr/5/karadeniz-ekonomik-isbirligi-orgutu-kei 
Tablo I: KEi Ülkelerinin Bazı Makro Ekonomik Göstergeleri (2015)

\begin{tabular}{|l|c|c|c|c|c|}
\hline Ülkeler & \multicolumn{1}{c|}{ GSYH (milyar\$) } & KBGSYH $^{*}$ (bin\$) & \multicolumn{1}{|c|}{ İhracat (milyar\$) } & İthalat (milyar\$) & Diş Açıklık \\
\hline Arnavut & 11,5 & 11,3 & 1,9 & 4,3 & 54 \\
Azerbaycan & 53,1 & 17,7 & 11,3 & 9,2 & 39 \\
Bulgaristan & 48,9 & 17,5 & 25,7 & 29,2 & 112 \\
Ermenistan & 10,5 & 8,3 & 1,4 & 3,2 & 44 \\
Gürcistan & 13,9 & 9,6 & 2,2 & 7,7 & 71 \\
Moldova & 6,5 & 5,0 & 1,9 & 3,9 & 89 \\
Romanya & 177,9 & 21,4 & 60,6 & 69,8 & 73 \\
Rusya & $1.326,1$ & 24,4 & 343,9 & 182,7 & 40 \\
Surbistan & 36,5 & 13,4 & 13,3 & 18,2 & 86 \\
Türkiye & 718,2 & 19,6 & 143,8 & 207,2 & 49 \\
Ukrayna & 90,6 & 7,9 & 38,1 & 37,5 & 83 \\
Yunanistan & 195,2 & 26,6 & 28,2 & 47,2 & 39 \\
\hline
\end{tabular}

http://databank.worldbank.org/data/home.aspx, http://comtrade.un.org/ $\left.{ }^{*}\right)$ Satın alma gücü paritesine göre hesaplanan değerdir.

KEİ ülkelerinin temel makroekonomik göstergeleri incelendiğinde (Tablo 1), Rusya ve Türkiye dışında, genel olarak ekonomilerinin büyük olmadı̆̆ı görülmektedir. Bununla birlikte, söz konusu ülkelerin kişi başına gelir ortalamasının (satın alma gücü paritesine göre) \$20.000 civarında olduğu söylenebilir. KEİ içinde kişi başına geliri en yüksek ülkeler Yunanistan, Rusya ve Romanyadır. Ekonomisi nispi olarak büyük olan Rusya ve Türkiye’nin diş ticaret hacimlerinin de büyüklüğü dikkat çekicidir.

Grafik I: KEi Ülkelerinin Dış Açıklık İndeksi (20I5)

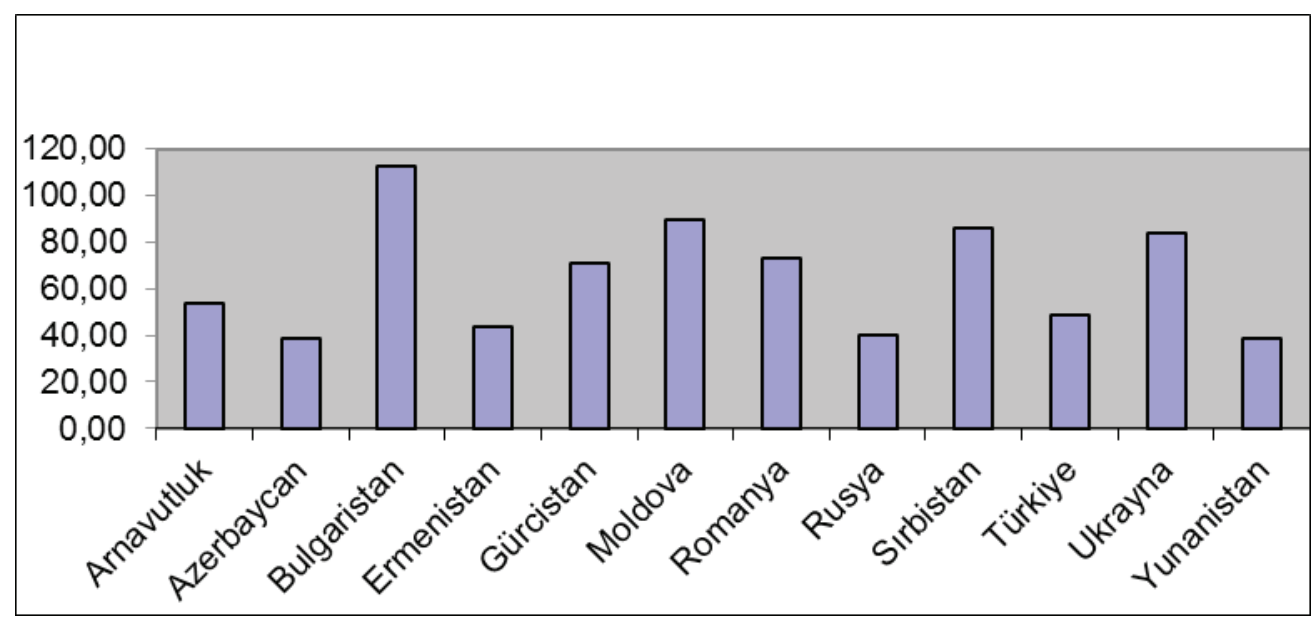

COMTRADE veri tabanı kullanılarak tarafımızca hazırlanmıştır. 
KEİ ekonomilerinin dışa açıklığı ${ }^{2}$ (Erkan ve Sarıçoban, 2014: 5) dikkate alındığında, en yüksek değere sahip ülkelerin Bulgaristan, Moldova, Sırbistan ve Ukrayna olduğu görülmektedir (Grafik 1). Bununla birlikte, Azerbaycan, Ermenistan, Rusya, Türkiye ve Yunanistan’ın dış açıklı̆̆ının nispi olarak düşük olduğu söylenebilir. KEİ üyesi ülkelerin çoğunluğunun geçiş ekonomileri olduğu dikkate alındığında, dış açıklık derecesinin tatminkâr düzeyde olduğu söylenebilir.

Bölgesel entegrasyon teorileri baz alındığında, KEİ’nin başlangıç aşamasından ileri gitmemiş bir örgüt olduğu görülmektedir. Söz konusu işbirliğe gereken önemin verilmesi ve işbirliğinin ekonomik-sosyal-kültürel-siyasi boyutlarının genişletilmesi suretiyle üye ülkelerin ekonomik kalkınma ve refah düzeylerinin artabileceği aşikardır.

\section{Karşılaştırmalı Üstünlükler Teorisi}

Ricardo’ya dayanan (1817) karşılaştırmalı üstünlük kavramı en eski uluslararası ticaret teorilerinden birisidir (Ricardo, 1817) ve ülkelerin belli mallardaki uzmanlaşma ve ihracat rekabet düzeylerini değerlendirmek maksadıyla yaygın olarak kullanılmaktadır.

Karşılaştırmalı üstünlüğe ilişkin çeşitli ekonomik düşüncelerin tarihi gelişimi anahtar kelimeleriyle birlikte Tablo 2'de verilmiştir.

Karşılaştırmalı üstünlük teorisi, uluslararası ticaretin arkasındaki itici gücün "mutlak" değil "karşılaştırmalı" avantaj olduğunu açıklamaktadır. Yani, bir siyasi otorite, ülkesinin tüm mallarda mutlak avantajı olsa bile (diğer bir deyişle bütün malları diğer ülkelere göre daha ucuza üretebiliyorsa da) karşılaştırmalı üstünlüğünün bulunduğu mallarda uzmanlaşmasının artması yoluyla uluslararası ticaretten yine de yararlanabilir (Leung ve Junning, 2007:3).

Karşılaştırmalı üstünlük, ticaretin tamamen sınırsız olduğu durumlarda dünya kaynaklarının (arazi, emek ve sermaye girdileri) daha verimli kullanması yoluyla ticaretin fayda sağlayabileceğini açıklamaktadır (Rooyen vd., 1993:3). Her ülke karşılaştırmalı üstünlüğe sahip ürünler üretmeli ve ihraç etmeli, karşılaştırmalı üstünlüğe sahip olmadığı ürünlerin ithalatını yapmalıdır. Karşılaştırmalı üstünlük, bir ülkenin aynı ürünün belirli bir kalitesiyle karşılaştırıldığında, diğer ülkelere kıyasla daha düşük karşılaştırmalı maliyet anlamına gelir ve bu durum ülkeye karşılaştırmalı üstünlük sağlamaktadır (Liping, 2009).

2 ((İhracat + İthalat $/$ GSYH $) \times 100)$ 
Tablo 2: Karşılaştırmalı Üstünlük Analizinin Temelleri

\begin{tabular}{|c|c|c|}
\hline $\begin{array}{l}\text { Yaklaşımlar } \\
\text { Klasik Politik Ekon }\end{array}$ & Anahtar Kavram(lar) & Mekanizma(lar) \\
\hline A. Smith & Verimlilik/Pazar büyüklüğü & Uzmanlaşma, rekabet \\
\hline D. Ricardo & Karşılaştırmalı üstünlük & Uluslararası ticaret \\
\hline J.S. Mill & Bebek sanayiler & Yaparak öğrenme \\
\hline J.S. Mill & Koruma politikası & Gelir dağılımı \\
\hline \multicolumn{3}{|l|}{ Neoklasik Modeller } \\
\hline Ricardian & Etkinlik & Tek anahtar kaynak kullanımı \\
\hline Heckscher-Ohlin & Faktör yoğunluğu & Birden fazla kaynak kullanımı \\
\hline Ricardo-Viner & Özel faktörler & Sektöre özel girdi kullanımı \\
\hline $\mathrm{H}-\mathrm{O}-\mathrm{Samuelson}$ & Tüketici talebi & Ürün tercihleri \\
\hline Salter-Swan & Döviz kurları & Ticarete konu olmayan mallar \\
\hline \multicolumn{3}{|c|}{ Karşılaştırmalı Üstünlüğe Meydan Okuma } \\
\hline Prebisch/Singer & İthalat-ikame & Diş ticaret hadleri \\
\hline A.O. Hirschman & Kalkınma stratejisi & Endüstri-içi bağlantılar \\
\hline Yeni ticaret teorileri & Stratejik politika & Dişsallıklar \\
\hline Michael Porter & Karşılaştırmalı üstünlük & Faktör yaratma, talep sinyali \\
\hline
\end{tabular}

William A. Masters, "Guidelines on National Comparative Advantage and Agriculture Trade" (APAP III, 1995), 6.

\section{Açıklanmış Karşılaştırmalı Üstünlük Katsayılarıyla Karşılaştırmalı Üstünlüğün Ölçümü}

Karşılaştırmalı üstünlük kavramının ölçülebilmesi bağlamında önemli eksiklikler bulunmaktadır. Söz konusu eksikliklerin giderilmesine yönelik en önemli hamle, karşılaştırmalı üstünlüklerin ve rekabet gücünün ölçümünde açıklanmış karşılaşmalı üstünlük katsayılarının (AKÜ) kullanılmasıdır (Sanidas ve Shin, 2011). Karşılaştırmalı üstünlükler teorisi ile karşılaştırmalı 
üstünlüklerin ve rekabet gücünün ölçümü arasındaki bağlantının ortaya koyulması şu sıralama ile olmaktadır:

$$
\mathrm{EŞ} \rightarrow \mathrm{KÜ} \rightarrow \mathrm{TÜT} \rightarrow \mathrm{AKÜ}
$$

EŞ: Ülkelerin ekonomik koşulları, KÜ: Karşılaştırmalı üstünlüklerin uluslararası örnekleri, TÜT: Uluslararası ticaret, üretim ve tüketim, AKÜ: Açıklanmış Karşılaştırmalı Üstünlük Katsayıları. Diyagrama göre, ülkelerin ekonomik koşullarınca belirlenen karşılaştırmalı üstünlükler uluslararası ticareti, üretim ve tüketimi (ihracat, ithalat) belirlemekte, bu da ülkelerin rekabet gücüne etki etmektedir (Ballance vd., 1987: 157).

Açıllanmış karşılaştırmalı üstünlükler düşüncesi ilk olarak Liesner (1958) tarafından ortaya atılmıştır. İngiltere’nin Ortak Pazar Ülkeleri ile rekabet gücünü karşılaştırmak için oluşturulmuş indeks, Balassa (1965) tarafından işlevsel hale getirilmiştir. Ülkelerin mevcut ticaret verilerinden yararlanılarak karşılaştırmalı üstünlügünü gösteren Balassa İndeksi, ülkeler arasındaki karşılaştırmalı üstünlüğ̈̈n nedenine inmeden, görünen bir avantaj farkı olup olmadığını açıklamayı amaçlamaktadır (Seymen, 2009).

İndeks, ülkenin belli bir sektör ihracatının toplam ihracatına oranının, aynı sektörün dünyadaki ihracatının dünya toplam ihracatına oranı olarak tanımlanabilir. Balassa İndeksi, herhangi bir malın (sektörün) ülkenin toplam ihracatındaki payının, söz konusu malın (sektörün) dünyanın (bir ülkenin veya bölgenin) toplam ihracatındaki payına oranını ifade eder. Diğer bir ifadeyle Balassa İndeksi, ülkenin bir maldaki yurtiçi uzmanlaşmasını (AKÜ indeksinin payı), dünyanın uzmanlaşmasıyla (AKÜ indeksinin paydası) karşılaştırır (Beningo, 2006).

“j” ülkesinin "t” döneminde " $k$ ” malındaki (sektöründeki) açıklanmış karşılaştırmalı üstünlük (AKÜ) katsayısı Balassa tarafından aşağıdaki gibi formüle edilmiştir (Balassa, 1965):

$$
\operatorname{BAKÜj}_{\mathrm{kt}}=\left(X_{k}^{j} / X_{t}^{j}\right) /\left(X_{k}^{w} / X_{t}^{w}\right)
$$

Vollrath’n Nispi İhracat Avantajı İndeksi (VAKÜ), Balassa İndeksinden farklı olarak ülkenin ve malın çifte hesabını önlemektedir.

$$
\operatorname{VAKÜj}{ }_{\mathrm{kt}}=\left(X_{k t}^{j} / X_{-k}^{j}\right) /\left(X_{k}^{-j} / X_{-k}^{-j}\right)
$$

$\mathrm{X}_{\mathrm{k}, \mathrm{t}}^{\mathrm{j}} \rightarrow$ " $\mathrm{t}$ ” döneminde " $\mathrm{k}$ ” malında “j” ülkesinin ihracatı

$\mathrm{X}_{-\mathrm{k}, \mathrm{t}}^{\mathrm{j}} \rightarrow$ "t" döneminde " $\mathrm{k}$ ” malı haricindeki “ $\mathrm{j}$ ” ülkesinin toplam ihracatı

$\mathrm{X}_{\mathrm{k}, \mathrm{t}}^{-\mathrm{j}} \rightarrow$ "t" döneminde $\mathrm{X}_{\mathrm{k}, \mathrm{t}}^{\mathrm{h}}$ hariç “ $\mathrm{k}$ ” malında dünya ihracatı

$\mathrm{X}_{-\mathrm{k}, \mathrm{t}}^{-\mathrm{j}} \rightarrow$ " $\mathrm{t}$ ” döneminde $\mathrm{X}_{\mathrm{k}, \mathrm{t}}^{\mathrm{j}}$ ve $\mathrm{X}_{-\mathrm{k}, \mathrm{t}}^{\mathrm{j}}$ haricinde dünya toplam ihracatı

VAKÜ indeks değerinin sonuçlarının yorumu, Balassa İndeksi ile aynıdır. 
Karşılaştırmalı üstünlüğün gücünü göstermek amacıyla AKÜ katsayısını 4 aşamada sinıflandırabiliriz (Hinloopen ve Marrevijk, 2001: 13). Buna göre, indeks değeri 0 ile 1 arasında ise söz konusu ülkenin belli ürün ihracatında karşılaştırmalı dezavantajı vardır. Diğer bir ifadeyle, ülkenin ihracat rekabet gücü yoktur. Bununla birlikte, indeks değeri l'den büyükse ülke sözü edilen ürünün ihracatında karşılaştırmalı üstünlüğe sahiptir. Bu üstünlük; indeks değerinin 1 ile 2 arasında olması durumunda zayıf, 2 ile 4 arasında olması durumunda orta, 4'den büyük olması durumunda da güçlü düzeydedir.

\section{Literatür Araştırması}

Tarafımızca yapılan literatür araştırmasında, Karadeniz Ekonomik İşbirliği Örgütü (KEİ) ile ilgili geniş bir bilimsel çalışma portföyüne rastlanmamıştır. Bu da, çalışmanın birkaç yerinde belirtildiği gibi, KEİ’ye küresel bazda yeterince önem verilmeyişinin göstergesidir.

KEİ ile ilgili bilimsel çalışma örnekleri genelde örgütsel yapı, kuruluş ve tarihsel gelişim, örgütün siyasi yapısı ve küresel-bölgesel siyasetteki önemi, enerji ekonomisi, ekonomik büyüme ve genel ekonomik özellikleri üzerinde yoğunlaşmıştır.

Literatür araştırmasında, KEİnin küresel bazda karşılaştırmalı üstünlüklerine ve ihracat rekabet gücü ilişkin herhangi bir bilimsel çalışmaya rastlanmamıştır. Bu bağlamda, bu çalışmada, KEİ üyesi ülkelerin ihracat rekabet profilinin ve karşılaştırmalı üstünlüklerinin ortaya koyulması maksadıyla bu bilimsel çalışmanın yapılması ve literatüre katkı sağlaması amaçlanmıştır.

\section{Yöntem}

Çalışmada öncelikle Türkiye ile KEİ ülkelerinin sektörel ihracat benzerliklerinin ortaya koyulması amacıyla "ihracat benzerlik indeksi" hesaplanmıştır. Burada amaç, küresel piyasalarda hangi ülkelerin ihracatının sektörel bazda Türkiye ile daha benzer olduğunun belirlenmesidir. İhracat benzerlik indeksinin hesaplanmasındaki bir diğer amaç da, hangi KEİ ülkelerinin, Türkiye’nin uluslararası piyasalarda rakibi olabileceğinin ortaya koyulmasıdır.

Çalışmada, ihracat benzerliklerinin hesaplanmasının ardından, 12 KEİ üyesinin 2000-2014 yılları arası ihracatındaki karşılaştırmalı üstünlüklerin (rekabet gücünün) ölçülebilmesi maksadıyla "Balassa İndeksi" ve "Vollrath İndeksi" (açıklanmış karşılaştırmalı üstünlük katsayıları) hesaplanmıştır. Açıklanmış karşılaştırmalı üstünlük katsayısı (AKÜ), UN Statistics Office ve Standart International Trade Classification (SITC) verileri kullanılarak (UN Comtrade ve PC TAS) hesaplanmaktadir ${ }^{3}$.

Ülkelerin sektörel ihracatındaki açıklanmış karşılaştırmalı üstünlük katsayıları "uygun ortalama” değerleri esas alınarak hesaplanmıştır. Uygun ortalama; bir serideki en yüksek ve en düşük

3 Tüm formüllerde X; ihracat, $M$; ithalat, $t$; dönem, $\mathrm{k}$; mal (sektör), $\mathrm{j}$; ülke 1, $\mathrm{m}$; ülke 2, w; dünya, u; birlik şeklinde sembolize edilmiştir. 
değerlerin elemine edilerek kalan serilerin aritmetik ortalamasının alınmasını ifade eder (http:// www.statistics.com/resources/glossary/t/trimmean.php). Yalnızca aritmetik ortalamanın kullanılması durumunda, bazı sektörlerin ihracat rakamlarının (dolayısı ile hesaplanan açıklanmış karşılaştırmalı üstünlük katsayılarının) dönemsel olarak çok düşük veya çok yüksek olabildiği/olabileceği düşünülerek, değerlendirmenin daha sağlıklı olabilmesi için "uygun ortalama” hesaplanmıştır (Küçükkiremitçi, 2006).

Bir sonraki adımda ise karşılaştırmalı üstünlüklerin/dezavantajın yıllara göre seyrini daha ayrıntılı bir şekilde analiz edebilmek ve uygun ortalamadan sapmaları ortaya koyabilmek amacıyla; Balassa’nın ve Vollrath’n açıklanmış karşılaştırmalı üstünlük katsayısının standart sapma ve değişkenlik katsayısı değerleri hesaplanmıştır. Çalışmada, değişkenlik katsayısının marjinal değeri 15 olarak kabul edilmiştir.

\section{Türkiye'nin KEi Ülkeleriyle İhracat Benzerlik İndeksi}

Bir ülkenin uluslararası piyasalarda rakiplerinin hangi ülkeler olduğunu belirlemek amacıyla ihracat benzerlik indeksi kullanılmaktadır. Bir ülke ile başka bir ülkenin küresel piyasalarda rakip olabilmesi için benzer ürün ve sektörlerin ihracatında yoğunlaşmış olmaları gerekmektedir. Bu nedenle, birbirleriyle ihracat benzerliği yüksek olan ülkelerin, ciddi bir rekabet durumuyla karşı karşıya oldukları söylenebilir.

İhracat benzerlik indeksi;

$$
\mathrm{ESI}=\sum \min \left[X_{k}(j w), X_{k}(m)\right] \times 100
$$

şeklinde formüle edilmektedir.

$\mathrm{X}_{\mathrm{k}}(j w) \rightarrow \mathrm{j}$ ülkesinin dünyaya gerçekleştirdiği $\mathrm{k}$ ürün grubu ihracat değerinin, dünyaya yaptığ toplam ihracat içindeki payı

$\mathrm{X}_{\mathrm{k}}(m w) \rightarrow \mathrm{m}$ ülkesinin dünyaya gerçekleştirdiği $\mathrm{k}$ ürün grubu ihracat değerinin, dünyaya yaptığı toplam ihracat içindeki payı

Mükemmel bir eşleşme varsa, yani, bir ülkenin ihracat yapısı diğer ülkenin ihracat yapısıyla tamamen aynı ise, indeks 100 değerini alır (Mikic, 2005: 16). Eşleşme yüksek ise rekabet derecesi de yüksektir. İki ülkenin söz konusu sektörde ihracatı yoksa indeks değeri sıfır olur (Trung, 2011: 15). Bu durumda, ülkelerin sözü edilen ürünlerin ihracatında herhangi bir rekabet durumundan söz edilemez (Rahman vd., 2004: 4).

Bu indeks ile iki ülke arasındaki ihracatın benzerliğinin zaman içindeki değişimi de gözlenebilir. Böylece ülkelerin ihracat yapısının ve ekonomik yapısının zaman içinde daha benzer ya da farklı hale gelme derecesi konusunda bir yorum yapılması mümkün olabilir. 
Tablo 3: Türkiye'nin KEi Ülkeleriyle İhracat Benzerlik İndeksi

\begin{tabular}{|l|c|l|c|l|c|}
\hline \multicolumn{2}{|c|}{2000} & \multicolumn{2}{c|}{2007} & \multicolumn{2}{c|}{2014} \\
\hline \multicolumn{1}{|c|}{ ÜLKE } & İNDEKS & \multicolumn{1}{c|}{ ÜLKE } & INDEKS & ÜLKE & INDEKS \\
\hline romanya & 0,63 & romanya & 0,68 & surbistan & 0,71 \\
yunanistan & 0,60 & bulgaristan & 0,60 & romanya & 0,64 \\
Surbistan & 0,57 & yunanistan & 0,59 & bulgaristan & 0,59 \\
bulgaristan & 0,53 & surbistan & 0,58 & yunanistan & 0,45 \\
moldova & 0,44 & ukrayna & 0,47 & ukrayna & 0,42 \\
arnavutluk & 0,44 & gürcistan & 0,41 & moldova & 0,34 \\
ukrayna & 0,38 & arnavutluk & 0,41 & gürcistan & 0,34 \\
gürcistan & 0,34 & moldova & 0,32 & ermenistan & 0,30 \\
ermenistan & 0,29 & rusya & 0,25 & rusya & 0,26 \\
rusya & 0,25 & ermenistan & 0,24 & arnavutluk & 0,22 \\
azerbaycan & 0,12 & azerbaycan & 0,19 & azerbaycan & 0,10 \\
\hline
\end{tabular}

COMTRADE veri tabanı kullanılarak tarafımızca hazırlanmıştır.

Çalışmada, Türkiye’nin KEİ ekonomileriyle ihracat benzerlik indeksi SITC Rev3 2 haneli ihracat verileri esas alınarak 2000, 2007 ve 2014 yıllarına yönelik hesaplanmıştır (Tablo 3). Hesaplanan yıllara yönelik ihracat benzerlik indeksi skorları incelendiğinde, KEİ ekonomileri arasında Türkiye ile benzerliği en yüksek olan ülkelerin Romanya, Bulgaristan, Sirbistan ve Yunanistan olduğu görülmektedir (Grafik 2). Özellikle Yunanistan ve Bulgaristan ile olan ihracat benzerliği son yıllarda nispi olarak azalmakta, Sirbistan ve Romanya ile olan benzerlik artmaktadır.

Türkiye'nin özellikle Sırbistan ve Romanya ile nispi benzerliği, söz konusu ülkelerin Türkiye’nin ihracat piyasaları açısından rekabet unsuru olduğunu göstermektedir.

Türkiye'nin ihracat benzerlik düzeyinin en az olduğu ülkelerin (Rusya, Arnavutluk, Azerbaycan vb.) daha çok hammadde yoğun ürünlerin ihracatında rekabet avantajına sahip olmaları dikkat çekicidir (Grafik 3). Özellikle, ihracatının önemli bir kısmını AB’ye gerçekleştiren ve aynı zamanda G8 ülkelerinden olan Rusya’nın Türkiye ile ihracat benzerlik indeksinin çok düşük olmasının (benzer malların ihracatının az olmasının), Türkiye'nin ihracatındaki rekabet gücü açısından olumlu bir durum olduğu ifade edilebilir. 
Grafik 2: Türkiye’nin En Yüksek Benzerliğe Sahip Olduğu 5 KEi Ülkesi

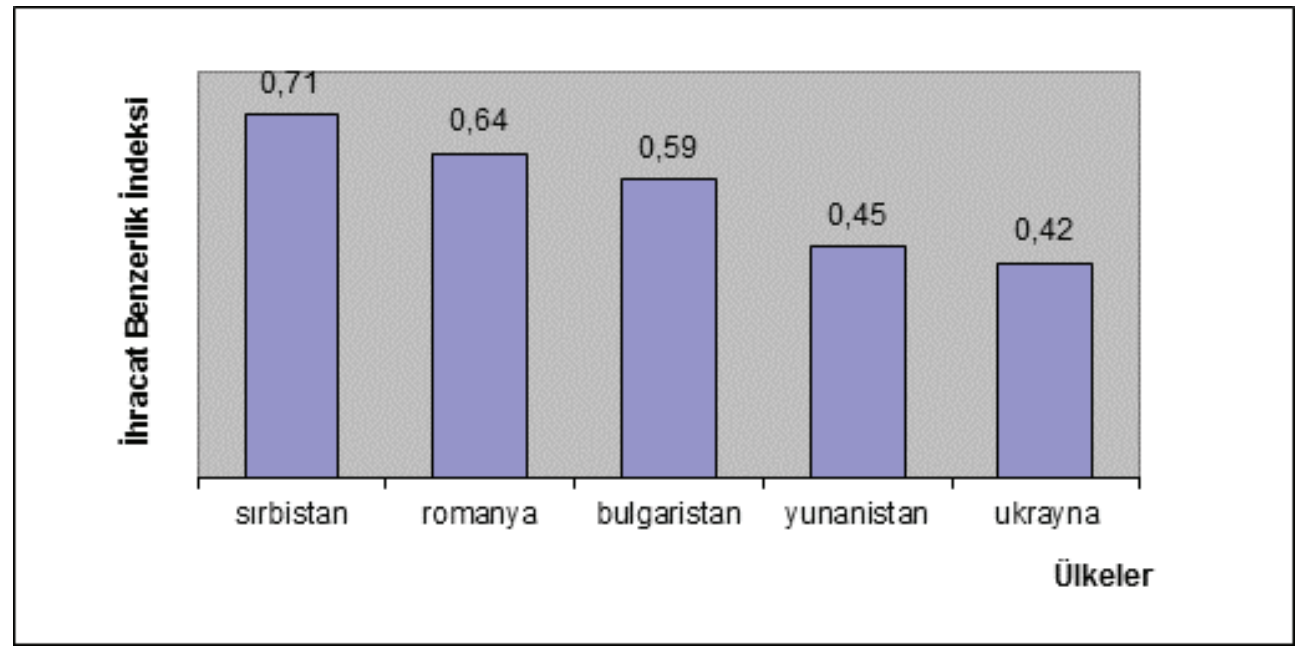

COMTRADE veri tabanı kullanılarak tarafımızca hazırlanmıştır.

Grafik 3: Türkiye'nin En Düşük Benzerliğe Sahip Olduğu 5 KEi Ülkesi

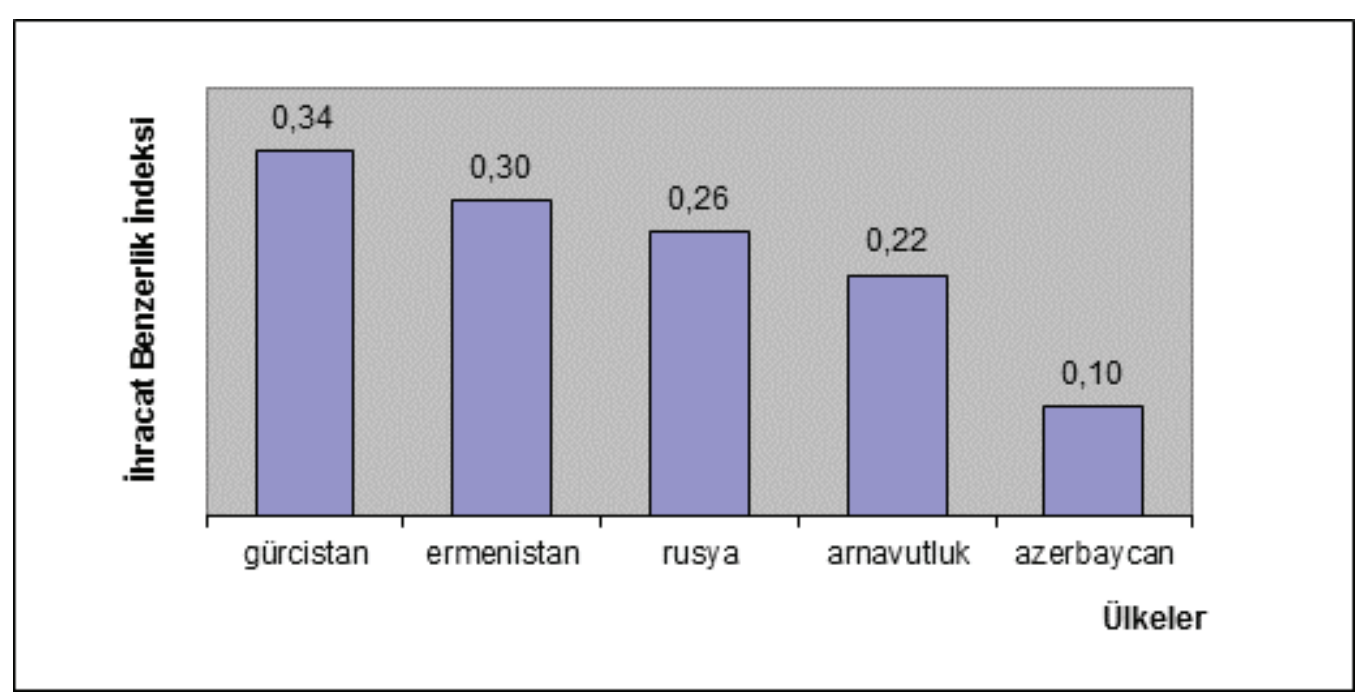

COMTRADE veri tabanı kullanılarak tarafımızca hazırlanmıştır.

\section{KEi Ülkelerinin İhracatındaki Karşılaştırmalı Üstünlükleri}

KEİ ülkelerinin ihracatındaki karşılaştırmalı üstünlüklerinin ölçülebilmesi maksadıyla Balassa’nın ve Vollrath’nn açıklanmış karşılaştırmalı üstünlük katsayıları (Balassa İndeksi ve Vollrath İndeksi) kullanılmıştır. 


\section{Balassa İndeksiyle KEi Ülkelerinin Karşılaştırmalı Üstünlüklerinin Analizi}

Çalışmada KEİ ülkelerinin 2000-2014 yılları sektörel ihracatına ilişkin açıklanmış karşılaştırmalı üstünlük katsayıları hesaplanmış ve sözü edilen ülkelerin güçlü derecede karşılaştırmalı üstünlüğe (ihracat rekabet gücüne) sahip oldukları ürün gruplarının Balassa İndeks değerleri Tablo 4’te verilmiştir. Tablo 4’te aynı zamanda indeks değerlerinin değişkenlik katsayıları (CV) da gösterilmiştir ${ }^{4}$.

Tabloda ayrıca, KEİ ülkelerinin küresel pazarlarda yüksek oranda karşılaştırmalı üstünlüğe sahip olduğu ürün gruplarının faktör yoğunlukları da gösterilmiştir ${ }^{5}$.

Buna göre, KEİ ülkelerinin genellikle hammadde yoğun ürün gruplarında küresel üstünlüklerinin güçlü derecede olduğu dikkat çekmektedir. Bununla birlikte, söz konusu ülkeler emek yoğun ve sermaye yoğun ürünlerin ihracatında da güçlü derecede karşılaştırmalı üstünlüklere (ihracat rekabet avantajına) sahiptirler.

KEİ ülkelerinden hiçbirisi katma değeri yüksek, inovatif ve teknolojik ürünlerin ihracatında güçlü derecede karşılaştırmalı üstünlüğe sahip değildir. Keza, ülkelerin yüksek oranda (güçlü derecede) karşılaştırmalı üstünlüğe sahip olduğu ürün grupları incelendiğinde Kolay Taklit Edilebilir ve Zor Taklit Edilebilir Araştırma Bazlı ürün gruplarının bulunmadığı gözlemlenmektedir. Bu durum, KEİ ülkelerinin ihracatındaki katma değerlerin düşük, ithalatındaki katma değerlerin yüksek olduğunu ortaya koymaktadır. Bu da, söz konusu ülkelerin yüksek düzeyde kalkınmışlığa sahip olmadıklarının önemli bir göstergesidir.

Tablo 4: KEi Ülkelerinin “Yüksek Oranda” Karşılaştırmalı Üstün Olduğu Ürün Grupları (Balassa İndeksi)

\begin{tabular}{|l|c|c|c|c|}
\hline ÜLKELER & Ürün Kodu & \multicolumn{1}{c|}{ BAKÜ } & \multicolumn{1}{c|}{ CV } & Faktör Yoğunluğu \\
\hline \multirow{3}{*}{ ARNAVUTLUK } & 21 & 6,96 & 40,41 & Hammadde Yoğun \\
& 29 & 5,17 & 37,86 & Hammadde Yoğun \\
& 84 & 5,39 & 56,25 & Emek Yoğun \\
& 85 & 18,66 & 59,37 & Emek Yoğun \\
\hline AZERBAYCAN & 33 & 7,54 & 19,81 & Hammadde Yoğun \\
\hline BULGARÍSTAN & 68 & 4,34 & 10,91 & Sermaye Yoğun \\
\hline & 11 & 12,22 & 29,89 & Sermaye Yoğun \\
& 28 & 7,49 & 30,67 & Hammadde Yoğun \\
ERMENISTAN & 35 & 11,32 & 76,36 & Sermaye Yoğun \\
& 66 & 6,04 & 73,70 & Emek Yoğun \\
\hline
\end{tabular}

4 Bir ürünün ihracatında karşılaştırmalı üstünlük (rekabet avantajı) olması durumunda, değişkenlik katsayısının da yüksek olmaması (kritik değer 15 kabul edilebilir) sağlıklı bir gösterge olarak kabul edilebilir.

5 Faktör yoğunluklarına göre ürünler 5 gruba ayrılmaktadır: Hammadde Yoğun, Emek Yoğun, Sermaye Yoğun, Kolay Taklit Edilebilir Araştırma Bazlı, Zor Taklit Edilebilir Araştırma Bazlı (Ek Tablo 1) 


\begin{tabular}{|c|c|c|c|c|}
\hline ÜLKELER & Ürün Kodu & BAKÜ & $\mathrm{CV}$ & Faktör Yoğunluğu \\
\hline \multirow{7}{*}{ GÜRCÍSTAN } & 00 & 5,78 & 132,27 & Hammadde Yoğun \\
\hline & 06 & 4,53 & 121,39 & Hammadde Yoğun \\
\hline & 11 & 15,25 & 26,82 & Sermaye Yoğun \\
\hline & 28 & 10,32 & 70,27 & Hammadde Yoğun \\
\hline & 35 & 4,03 & 77,47 & Sermaye Yoğun \\
\hline & 56 & 14,61 & 24,26 & Hammadde Yoğun \\
\hline & 97 & 5,09 & 73,91 & Belirtilmemiş \\
\hline \multirow{8}{*}{ MOLDOVA } & 05 & 6,22 & 10,21 & Hammadde Yoğun \\
\hline & 06 & 4,12 & 43,18 & Hammadde Yoğun \\
\hline & 11 & 21,68 & 46,83 & Sermaye Yoğun \\
\hline & 12 & 4,05 & 65,60 & Sermaye Yoğun \\
\hline & 21 & 6,62 & 146,01 & Hammadde Yoğun \\
\hline & 22 & 8,68 & 31,37 & Hammadde Yoğun \\
\hline & 27 & 4,42 & 73,01 & Hammadde Yoğun \\
\hline & 42 & 5,96 & 32,07 & Hammadde Yoğun \\
\hline \multirow{2}{*}{ ROMANYA } & 00 & 5,51 & 14,37 & Hammadde Yoğun \\
\hline & 85 & 5,48 & 41,14 & Emek Yoğun \\
\hline \multirow{2}{*}{ RUSYA } & 34 & 7,80 & 30,06 & Hammadde Yoğun \\
\hline & 56 & 5,41 & 14,43 & Hammadde Yoğun \\
\hline \multirow{7}{*}{ SIRBİSTAN } & 00 & 4,03 & 46,18 & Hammadde Yoğun \\
\hline & 04 & 6,24 & 23,34 & Hammadde Yoğun \\
\hline & 05 & 4,56 & 6,04 & Hammadde Yoğun \\
\hline & 06 & 6,50 & 19,32 & Hammadde Yoğun \\
\hline & 21 & 4,59 & 11,46 & Hammadde Yoğun \\
\hline & 35 & 8,07 & 36,35 & Sermaye Yoğun \\
\hline & 62 & 4,16 & 3,38 & Sermaye Yoğun \\
\hline \multirow{4}{*}{ TÜRKİYE } & 05 & 5,18 & 16,08 & Hammadde Yoğun \\
\hline & 27 & 4,58 & 35,44 & Hammadde Yoğun \\
\hline & 65 & 5,97 & 7,64 & Emek Yoğun \\
\hline & 84 & 6,93 & 28,60 & Emek Yoğun \\
\hline \multirow{4}{*}{ UKRAYNA } & 04 & 4,42 & 54,57 & Hammadde Yoğun \\
\hline & 42 & 5,92 & 36,62 & Hammadde Yoğun \\
\hline & 56 & 7,69 & 33,33 & Hammadde Yoğun \\
\hline & 67 & 8,69 & 14,96 & Sermaye Yoğun \\
\hline \multirow{3}{*}{ YUNANISTAN } & 05 & 4,67 & 14,35 & Hammadde Yoğun \\
\hline & 12 & 6,54 & 20,28 & Sermaye Yoğun \\
\hline & 26 & 5,25 & 24,63 & Emek Yoğun \\
\hline
\end{tabular}

COMTRADE veri tabanı kullanılarak tarafımızca hazırlanmıştır. 
Tablo 5’te KEİ ülkelerinin 2000-2014 yılları arasında "Yüksek Oranda Karşılaştırmalı Üstünlüğe” sahip oldukları Vollrath İndeks sonuçları görülmektedir. Balassa İndeksi sonuçlarıyla karşılaştırıldığında, Vollrath İndeksi sonuçları, KEİ ülkelerinin daha fazla ürün grubunda karşılaştırmalı üstünlüğe sahip olduğunu göstermektedir. Bununla birlikte, Balassa İndeksi gibi, Vollrath indeksi sonuçları da KEİ ülkelerinin tamamının katma değeri nispi olarak düşük ürün gruplarında (hammadde, emek, sermaye) ihracat rekabet güçlerinin bulunduğunu ortaya koymaktadir.

Tablo 5: KEi Ülkelerinin “Yüksek Oranda” Karşılaştırmalı Üstün Olduğu Ürün Grupları (Vollrath İndeksi)

\begin{tabular}{|c|c|c|c|c|}
\hline ÜLKELER & Ürün Kodu & VAKÜ (Ort.) & $\mathrm{CV}$ & Faktör Yoğunluğu \\
\hline \multirow{6}{*}{ ARNAVUTLUK } & 21 & 10,80 & 40,54 & Hammadde Yoğun \\
\hline & 28 & 5,39 & 34,33 & Hammadde Yoğun \\
\hline & 29 & 8,11 & 38,81 & Hammadde Yoğun \\
\hline & 61 & 5,38 & 53,49 & Emek Yoğun \\
\hline & 84 & 11,18 & 63,43 & Emek Yoğun \\
\hline & 85 & 36,99 & 64,31 & Emek Yoğun \\
\hline \multirow{2}{*}{ AZERBAYCAN } & 33 & 102,34 & 53,46 & Hammadde Yoğun \\
\hline & 43 & 5,36 & 78,67 & Hammadde Yoğun \\
\hline \multirow{7}{*}{ BULGARİSTAN } & 04 & 4,20 & 38,22 & Hammadde Yoğun \\
\hline & 12 & 6,08 & 32,45 & Sermaye Yoğun \\
\hline & 22 & 5,79 & 36,19 & Hammadde Yoğun \\
\hline & 35 & 5,43 & 94,05 & Sermaye Yoğun \\
\hline & 56 & 4,73 & 60,68 & Hammadde Yoğun \\
\hline & 68 & 7,48 & 12,95 & Sermaye Yoğun \\
\hline & 84 & 5,20 & 37,00 & Emek Yoğun \\
\hline \multirow{8}{*}{ ERMENISTAN } & 11 & 20,92 & 32,37 & Sermaye Yoğun \\
\hline & 12 & 5,11 & 147,47 & Sermaye Yoğun \\
\hline & 28 & 13,64 & 32,70 & Hammadde Yoğun \\
\hline & 35 & 18,28 & 78,06 & Sermaye Yoğun \\
\hline & 66 & 11,94 & 88,79 & Emek Yoğun \\
\hline & 67 & 4,19 & 66,97 & Sermaye Yoğun \\
\hline & 68 & 6,78 & 48,64 & Sermaye Yoğun \\
\hline & 97 & 5,87 & 79,17 & Belirtilmemiş \\
\hline \multirow{9}{*}{ GÜRCISTAN } & 00 & 5,90 & 132,72 & Hammadde Yoğun \\
\hline & 05 & 6,00 & 34,30 & Hammadde Yoğun \\
\hline & 06 & 7,22 & 123,64 & Hammadde Yoğun \\
\hline & 11 & 27,07 & 31,00 & Sermaye Yoğun \\
\hline & 28 & 19,84 & 75,86 & Hammadde Yoğun \\
\hline & 35 & 6,29 & 78,80 & Sermaye Yoğun \\
\hline & 56 & 23,64 & 24,50 & Hammadde Yoğun \\
\hline & 67 & 5,12 & 38,34 & Sermaye Yoğun \\
\hline & 97 & 8,23 & 75,62 & Belirtilmemiş \\
\hline
\end{tabular}




\begin{tabular}{|c|c|c|c|c|}
\hline ÜLKELER & Ürün Kodu & VAKÜ (Ort.) & $\mathrm{CV}$ & Faktör Yoğunluğu \\
\hline \multirow{8}{*}{ MOLDOVA } & 05 & 6,22 & 10,21 & Hammadde Yoğun \\
\hline & 06 & 4,12 & 43,18 & Hammadde Yoğun \\
\hline & 11 & 21,68 & 46,83 & Sermaye Yoğun \\
\hline & 12 & 4,05 & 65,60 & Sermaye Yoğun \\
\hline & 21 & 6,62 & 146,01 & Hammadde Yoğun \\
\hline & 22 & 8,68 & 31,37 & Hammadde Yoğun \\
\hline & 27 & 4,42 & 73,01 & Hammadde Yoğun \\
\hline & 42 & 5,96 & 32,07 & Hammadde Yoğun \\
\hline \multirow{2}{*}{ ROMANYA } & 00 & 5,51 & 14,37 & Hammadde Yoğun \\
\hline & 85 & 5,48 & 41,14 & Emek Yoğun \\
\hline \multirow{5}{*}{ RUSYA } & 24 & 5,12 & 15,68 & Hammadde Yoğun \\
\hline & 32 & 4,30 & 14,88 & Hammadde Yoğun \\
\hline & 33 & 11,82 & 14,41 & Hammadde Yoğun \\
\hline & 34 & 18,70 & 35,40 & Hammadde Yoğun \\
\hline & 56 & 10,21 & 13,75 & Hammadde Yoğun \\
\hline \multirow{7}{*}{ SIRBISTAN } & 00 & 4,06 & 46,35 & Hammadde Yoğun \\
\hline & 04 & 6,57 & 24,55 & Hammadde Yoğun \\
\hline & 05 & 4,76 & 6,32 & Hammadde Yoğun \\
\hline & 06 & 6,63 & 19,63 & Hammadde Yoğun \\
\hline & 21 & 4,61 & 11,53 & Hammadde Yoğun \\
\hline & 35 & 8,24 & 37,00 & Sermaye Yoğun \\
\hline & 62 & 4,27 & 3,53 & Sermaye Yoğun \\
\hline \multirow{4}{*}{ TÜRKIYE } & 05 & 5,18 & 16,08 & Hammadde Yoğun \\
\hline & 27 & 4,58 & 35,44 & Hammadde Yoğun \\
\hline & 65 & 5,97 & 7,64 & Emek Yoğun \\
\hline & 84 & 6,93 & 28,60 & Emek Yoğun \\
\hline \multirow{7}{*}{ UKRAYNA } & 04 & 7,44 & 59,53 & Hammadde Yoğun \\
\hline & 22 & 4,99 & 43,57 & Hammadde Yoğun \\
\hline & 27 & 5,21 & 18,95 & Hammadde Yoğun \\
\hline & 28 & 4,75 & 55,22 & Hammadde Yoğun \\
\hline & 42 & 9,72 & 39,87 & Hammadde Yoğun \\
\hline & 56 & 12,59 & 34,40 & Hammadde Yoğun \\
\hline & 67 & 20,26 & 18,23 & Sermaye Yoğun \\
\hline \multirow{5}{*}{ YUNANISTAN } & 05 & 7,80 & 15,84 & Hammadde Yoğun \\
\hline & 12 & 10,49 & 21,18 & Sermaye Yoğun \\
\hline & 26 & 8,34 & 25,42 & Emek Yoğun \\
\hline & 27 & 4,65 & 36,38 & Hammadde Yoğun \\
\hline & 42 & 6,14 & 46,93 & Hammadde Yoğun \\
\hline
\end{tabular}

COMTRADE veri tabanı kullanılarak tarafımızca hazırlanmıştır. 
Grafik 4, KEİ bölgesindeki ihracatında karşılaştırmalı üstünlüklerin en yüksek olduğu 20 ürün gösterilmiştir. KEİ bölgesinde özellikle "petrol ve ürünleri” ihracatındaki çok yüksek derecedeki karşılaştırmalı üstünlük durumu dikkat çekicidir. Bununla birlikte, söz konusu ülkeler topluluğu, ayakkabı, içki, gübre, demir-çelik, doğalgaz gibi ürünlerin ihracatında da küresel rekabet avantajına sahiptir. Daha önce de değinildiği üzere, KEİ bölgesindeki ihracatta karşılaştırmalı üstünlükler daha çok hammadde, emek ve sermaye yoğun ürünlere dayanmaktadır.

Grafik 4: KEI Bölgesinde İhracat Karşılaştırmalı Üstünlüklerin En Yüksek Olduğu 20 Ürün Grubu (SITC Rev3 2 Hane, 2000-20I4 Ort.)

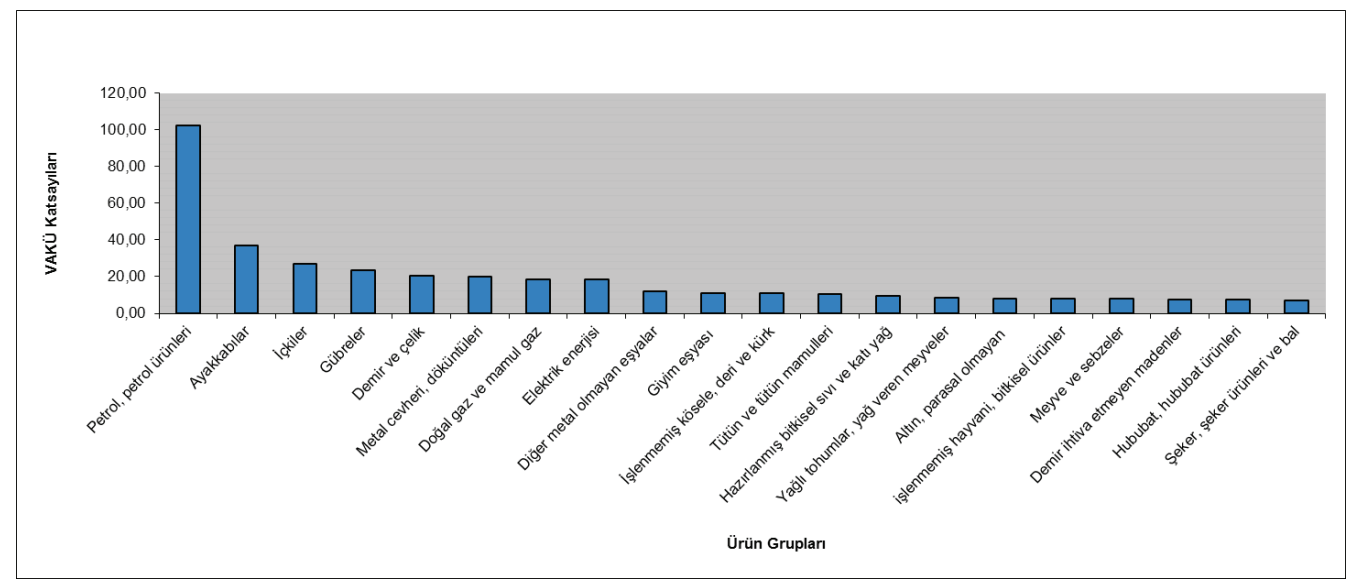

\section{Sonuç}

Açıklanmış karşılaştırmalı üstünlükler (Balassa İndeksi ve Vollrath İndeksi) yardımıyla Karadeniz Ekonomik İşbirliği Örgütü (KEİ) ihracatının ürün ve faktör yoğunluğu bazında karşılaştırmalı üstünlüklerini ve rekabet gücünü ortaya koyabilmek amacıyla yapılan bu çalışmadan elde edilen bulgular; KEİ ekonomilerinin genel olarak hammadde, emek ve sermaye yoğun ürünlerin ihracatında güçlü derecede karşılaştırmalı üstünlüğe sahip olduğunu (uzmanlaştığını) göstermektedir.

Örgüt üyelerinden hiçbirisinin katma değeri ve teknoloji donanımı yüksek ar-ge bazlı ürünlerin ihracatında güçlü derecede karşılaştırmalı üstünlüğe sahip olmaması dikkat çekicidir. Bu durum, KEİ ülkelerinin ihracatındaki katma değerlerin düşük, ithalatındaki katma değerlerin yüksek olduğunu ortaya koymaktadır. İhracatındaki karşılaştırmalı üstünlüklerin daha çok katma değeri düşük ürünlere dayanması, bilimsel ve teknolojik ürünlerde sözü edilen ülkeleri dışa bağımlı hale getirmektedir. Bu durum, karşılaştırmalı üstünlükleri hammadde ve emek yoğun malların ihracatına dayanan söz konusu ülkelerin dış açık vermesini ve dış ticaret hadlerinin aleyhte olmasını kaçınılmaz kılacaktır. 
KEİ ekonomilerinin karşılaştırmalı üstünlüklerinin daha çok hammadde ve emek donanımlarıyla açıklanması, özellikle kolay taklit edilebilir ve zor taklit edilebilir araştırma bazlı ürün gruplarının üretiminde ve ihracatında uzmanlaşamamış olması, küresel rekabet güçlerinin de zayıf olmasını beraberinde getirmektedir. Bu da, söz konusu ülkelerin kalkınmışlık düzeylerinin yükselmesinde önemli bir engel teşkil etmektedir.

KEİnin, bölgesel entegrasyon bağlamında, başlangıç aşamasından ileri gitmemiş bir örgüt olduğu şüphesizdir. KEİ’ye daha fazla önem verilmesi ve işbirliğinin ekonomik-sosyal-kültürelsiyasi boyutlarının genişletilmesi, üye ülkelerin ekonomik kalkınma ve refah düzeylerinin artabilecektir.

Dünyada güç dengelerinin sürekli değiştiği, belli yükselen ekonomilerin küresel piyasalarda daha fazla söz sahibi olmaya başladığı günümüzde, söz konusu ülkelerin dünya ihracatından ve katma değerinden daha fazla pay alabilmesi için; markalaşmaya, inovasyona ve teknolojiye daha fazla yatırım yapıp, emek verimliliğini arttırmak suretiyle dışa daha az bağımlı bir dış ticaret stratejisi geliştirmesi gerekir. Böylelikle, Karadeniz Ekonomik İşbirliği Örgütü küresel çapta daha etkin ve sözü geçen bir topluluk haline gelebilecektir. 


\section{Kaynakça}

Ballance, R. H., Forstner, H and Murray, T. (1987) "Consistency Tests of Alternative Measures of Comparative Advantage" The Review of Economics and Statistics, 69, no. 2, 157-161.

Balassa, B. (1965) "Trade Liberalization and Revealed Comparative Advantage" The Manchester School of Economic and Social Studies, 33, no. 2, 99-123.

Beningo, S. (2006) "Trade and Transportation Between the United States and China, and Between the United States and India" Presentattion at the 2006 Conference of the Society of Government Economists, Washington.

Erkan, B and Sarıçoban, K. (2014) "Comparative Analysis of the Competitiveness in the Export of ScienceBased Goods Regarding Turkey and the EU+13 Countries" International Journal of Business and Social Science, 5, no. 1, 1-14.

Ertürk, E. (2002) Uluslararası İktisadi Birleşmeler. Bursa: Vipaş Yay..

Güran, N. ve Aktürk, İ. (1995) Uluslararası İktisadi Kuruluşlar. İzmir: Karınca Mat..

Hinloopen, J. and van Marrewijk, C. (2001) “On the empirical distribution of the Balassa Index" Review of World Economics, 137, no. 1, 1-35.

Hufbauer, G. C. and Chilas, J. G. (1974) "Specialization by Industrial Countries: Extent and Consequences" Presentation at The International Division of Labour: Problems and Perspectives-International Symposium, Germany.

Küçükkiremitçi, O. (2006) "Sanayi Sektörünün Dış Ticaret Performansının Rekabet Gücüne Göre Değerlendirilmesi (1995-2005 Dönemi)" Presentation at the T.C. İnönü Üniversitesi İ.İ.B.F. Ulusal Bağımsızlık İçin Türkiye İktisat Politikaları Kurultayı, Malatya, Haziran 13-16.

Leung, P. and Junning, C. (2007) "A Review of Comparative Advantage Assessment Approaches in Relation to Aquaculture Development" Species and System Selection for Sustainable Aquaculture, 3, 1-23.

Liping, W. (2009) “Comparative Advantage Theory and Its Revelation to China’s Foreign Trade” Presentation at the International Conference on Management and Science (MASS), Beijing, China, September $20-22$.

Masters, W. A. (1995) "Guidelines on National Comparative Advantage and Agriculture Trade" APAP III, $1-80$.

Mikic, M. (2005) "Commonly Used Trade Indicators:A Note" ARTNeT Capacity Building Workshop on Trade Research, UNESCAP, 1-22.

Rahman, M. M., Zheng, Z. and Arjuman A. L. (2004) "The Trade Performance of Bangladesh in Clothing" China-USA Business Review, 3, no. 3, 1-27.

Ricardo, D. (1817) "On The Principles of Political Economy and Taxation.", http://www.econlib.org/ LIBRARY/Ricardo/ricP.html (Son erișim: 02.12.2016)

Sanidas, E. and Shin, Y. (2011) "Comparison of Revealed Comparative Advantage Indices with Application to Trade Tendencies of East Asian Countries." 2011. http://www.akes.or.kr/eng/papers(2010)/24. full.pdf (Son erişim: 14.11.2016)

Seymen, D. (2009) Türkiye’nin Dış Ticaret Yapısı ve Rekabet Gücü. İzmir: DEÜ Yay.

Trung, N. T. (2012) "Vietnam' s International Trade Regime and Comparative Advantage" Centre for ASEAN Studies (CAS)- Centre for International Management and Development Antwerp (CIMDA), 1-20.

Van Rooyen, C.J., Esterhuizen, D. and Doyer, O.T. (1999) "How Competitive is Agribusiness in the South African Food Commodity Chain?” Department of Agricultural Economics, Extension and Rural Development, University of Pretoris, 1-9.

http://www.statistics.com/resources/glossary/t/trimmean.php (Son erişim: 11.11.2016)

http://ab.gtb.gov.tr/5/karadeniz-ekonomik-isbirligi-orgutu-kei (Son erişim: 11.11.2016)

http://www.comtrade.un.org (Son erişim: 11.11.2016)

http://databank.worldbank.org/data/home.aspx (Son erişim: 11.11.2016) 
Ek

Ek Tablo I: SITC Teknoloji Sinıflandırması

\begin{tabular}{|c|c|}
\hline \multicolumn{2}{|r|}{ Hammadde Yoğun Mallar } \\
\hline SITC 0 & Canlı hayvanlar ve gida maddeleri \\
\hline SITC 2 (26 hariç) & Tarımsal hammaddeler \\
\hline SITC 3 (35 hariç) & Mineral yakitlar ve mineral yağlar \\
\hline SITC 4 & Hayvansal ve bitkisel yağlar \\
\hline SITC 56 & Gübreler \\
\hline \multicolumn{2}{|r|}{ Emek Yoğun Mallar } \\
\hline SITC 26 & Dokumaya elverişli lifler (elyaflar) \\
\hline SITC $6(62,67,68$ hariç $)$ & İmalat malları \\
\hline SITC $8(87,88$ hariç $)$ & Diğer üretim malları \\
\hline \multicolumn{2}{|r|}{ Sermaye Yoğun Mallar } \\
\hline SITC 1 & İçkiler, tütün ve mamulleri \\
\hline SITC 35 & Elektrik enerjisi \\
\hline SITC 53 & Boyacılıkta kullanılan ürünler \\
\hline SITC 55 & Uçucu yağlar, rezinoitler, parfümeri, kozmetik \\
\hline SITC 62 & Kauçuk eşya \\
\hline SITC 67 & Demir ve çelik \\
\hline SITC 68 & Demir ihtiva etmeyen madenler \\
\hline SITC 78 & Kara taşıtları \\
\hline \multicolumn{2}{|r|}{ Kolay Taklit Edilen Araştırma Bazlı Mallar } \\
\hline SITC 51 & Organik kimyasal ürünler \\
\hline SITC 52 & İnorganik kimyasal ürünler \\
\hline SITC 54 & Tip ve eczacılık ürünleri \\
\hline SITC 58 & İlk haliyle olmayan plastikler \\
\hline SITC 59 & Kimyasal maddeler ve ürünler \\
\hline SITC 75 & Büro makineleri, otomatik veri işleme makinesi \\
\hline SITC 76 & Haberleşme, sesi kaydetme ve kaydedilen sesi tekrar veren alet \\
\hline \multicolumn{2}{|r|}{ Zor Taklit Edilen Araştırma Bazı Mallar } \\
\hline SITC 57 & İlk haliyle plastikler \\
\hline SITC $7(75,76,78$ hariç $)$ & Makineler ve ulaşım araçları \\
\hline SITC 87 & Mesleki, bilimsel ölçü ve kontrol cihazları \\
\hline SITC 88 & Fotoğraf malzemeleri, optik eşyalar, saatler \\
\hline
\end{tabular}

Gary C. H. and John G. C. (1974) "Specialization by Industrial Countries: Extent and Consequences" (presentation, The International Division of Labour: Problems and Perspectives-International Symposium, Germany). 
Ek Tablo 2: SITC Rev3 2 Hane Ürün Grupları

\begin{tabular}{|c|c|c|c|}
\hline SITC & ÜRÜN GRUPLARI & SITC & ÜRÜN GRUPLARI \\
\hline 00 & Canlı hayvanlar & 56 & Gübreler (272. grubun dişındakiler) \\
\hline 01 & Et ve et ürünleri & 57 & İlk şekildeki plastikler \\
\hline 02 & Süt, süt ürünleri ve yumurtalar & 58 & İlk şekilde olmayan plastikler \\
\hline 03 & Balıklar ve diğer deniz ürünleri & 59 & $\begin{array}{l}\text { Başka yerlerde belirtilmeyen kimyasal } \\
\text { maddeler ve ürünler }\end{array}$ \\
\hline 04 & Hububat, hububat ürünleri & 61 & $\begin{array}{l}\text { Başka yerde belirtilmeyen işlenmiş deri ve } \\
\text { kürkler }\end{array}$ \\
\hline 05 & Meyve ve sebzeler & 62 & Kauçuktan eşya \\
\hline 06 & Şeker, şeker ürünleri ve bal & 63 & Mantar ve ahşap eşya (mobilya hariç) \\
\hline 07 & Kahve, çay, kakao, baharat ve ürünleri & 64 & Kağıt, karton ve kağıt hamurundan eşya \\
\hline 08 & Hayvanlar için gıda maddeleri & 65 & Diğer tekstil iplik, kumaş, şekil ver. mens \\
\hline 09 & Çeşitli yenilebilir ürünler & 66 & Diğer metal olmayan eşyalar \\
\hline 11 & İçkiler & 67 & Demir ve çelik \\
\hline 12 & Tütün ve tütün mamulleri & 68 & Demir ihtiva etmeyen madenler \\
\hline 21 & İşlenmemiş kösele, deri ve kürk & 69 & $\begin{array}{l}\text { Başka yerde belirtilmeyen madenden mamul } \\
\text { eşya }\end{array}$ \\
\hline 22 & Yağlı tohumlar, yağ veren meyveler & 71 & Güç üreten makineler ve araçlar \\
\hline 23 & Ham kauçuk & 72 & Belirli sanayiler için özel makineler \\
\hline 24 & Mantar, odun ve kereste & 73 & Metal işleme makineleri \\
\hline 25 & Kağıt hamuru ve kullanılmış kağıt & 74 & $\begin{array}{l}\text { Diğer genel endüstri makine/cihazların } \\
\text { aksamları }\end{array}$ \\
\hline 26 & Dokuma elyafi ve bunların artıkları & 75 & Büro ve otomatik veri işleme makineleri \\
\hline 27 & $\begin{array}{l}\text { Ham gübre ve madenler (kömür, petrol ve } \\
\text { değerli taşlar hariç) }\end{array}$ & 76 & $\begin{array}{l}\text { Haberleşme, ses kaydetme ve sesi tekrar } \\
\text { vermeye yarayan cihaz ve araçlar }\end{array}$ \\
\hline 28 & Metal cevheri, döküntüleri, hurdaları & 77 & $\begin{array}{l}\text { Elektrik makineleri, cihazları ve aletleri, vb. } \\
\text { aksam, parçaları }\end{array}$ \\
\hline 29 & $\begin{array}{l}\text { Başka yerde belirtilmeyen işlenmemiş } \\
\text { hayvani, bitkisel ürünler }\end{array}$ & 78 & Motorlu kara taşıtları \\
\hline 32 & Taş kömürü, kok kömürü ve biriket kömürü & 79 & Diğer taşıt araçları \\
\hline 33 & Petrol, petrolden elde edilen ürün & 81 & $\begin{array}{l}\text { Prefafabrik yapılar; sıhhi su tesisatı, 1sıtma ve } \\
\text { sabit aydınlatma cihazları }\end{array}$ \\
\hline 34 & Doğal gaz ve mamul gaz & 82 & Mobilya; yatak takımı, yastıklar \\
\hline 35 & Elektrik enerjisi & 83 & Seyahat eşyası, el çantaları vb. taşıyıcı eşya \\
\hline 41 & Hayvansal sıvı ve katı yağlar & 84 & Giyim eşyası ve bunların aksesuarları \\
\hline 42 & Hazırlanmış bitkisel sıvı ve katı yağ & 85 & Ayakkabilar \\
\hline 43 & İşlenmiş sıv1, katı yağlar; mumlar & 87 & $\begin{array}{l}\text { Başka yerde belirtilmeyen mesleki, ilmi, } \\
\text { kontrol alet ve cihazlar }\end{array}$ \\
\hline 51 & Organik kimyasal ürünler & 88 & Fotograf malzemesi, optik eşya, saatler \\
\hline 52 & İnorganik kimyasal ürünler & 89 & $\begin{array}{l}\text { Başka yerde belirtilmeyen çeşitli mamul } \\
\text { eşyalar }\end{array}$ \\
\hline 53 & Debagat ve boyacılıkta kull. ürün & 96 & $\begin{array}{l}\text { Tedavülde olmayan metal paralar (altın } \\
\text { olanlar hariç) }\end{array}$ \\
\hline 54 & Tıp ve eczacılık ürünleri & 97 & Altın,parasal olmayan (altın madeni hariç) \\
\hline
\end{tabular}

\section{COMTRADE veri tabanı}


